\title{
Modelling the Mass Transfer Kinetics of Battered and Breaded Fish Nuggets during Deep-Fat Frying at Different Frying Temperatures
}

\author{
Wei Zhang, ${ }^{1,2}$ Jiwang Chen $\mathbb{D}^{1,},{ }^{1,2}$ Yi Yue, ${ }^{1}$ Zhenzhou Zhu, ${ }^{1,2}$ E Liao, ${ }^{1,2}$ and Wenshui Xia ${ }^{3}$ \\ ${ }^{1}$ College of Food Science and Engineering, Wuhan Polytechnic University, Wuhan, Hubei 430023, China \\ ${ }^{2}$ Key Laboratory for Deep Processing of Major Grain and Oil (Wuhan Polytechnic University), Ministry of Education, Wuhan, \\ Hubei 430023, China \\ ${ }^{3}$ School of Food Science and Technology, Jiangnan University, Wuxi, Jiangsu 214122, China
}

Correspondence should be addressed to Jiwang Chen; jiwangchen1970@126.com

Received 10 June 2020; Revised 10 November 2020; Accepted 13 November 2020; Published 26 November 2020

Academic Editor: Vicente M. G mez L pez

Copyright (c) 2020 Wei Zhang et al. This is an open access article distributed under the Creative Commons Attribution License, which permits unrestricted use, distribution, and reproduction in any medium, provided the original work is properly cited.

\begin{abstract}
Battered and breaded fish nuggets (BBFNs) were fried at three different temperatures $\left(160,170\right.$, and $\left.180^{\circ} \mathrm{C}\right)$ for $30-180 \mathrm{~s}$ to study the mass transfer kinetics of moisture loss and fat absorption. The mass transfer mechanism was investigated through an analysis of microstructure, surface oil (SO), and penetrated surface oil (PSO) contents of fried BBFNs. The results showed that Fick's second law of diffusion and the first-order kinetic model could well describe the kinetics of moisture loss and fat absorption of the crust, respectively. Transfer coefficients of the two mass transports significantly increased with an increase in the frying temperature $(P<0.05)$. With the increase in the frying temperature, pore size of the crust increased. The PSO content of the crust also increased with elevated frying temperature. These results suggest that frying temperature affects the moisture loss and fat absorption kinetics of the crust by changing its microstructure.
\end{abstract}

\section{Introduction}

Deep-fat frying is widely used in the cooking of household dishes and the production of fast food items [1]. Frying in hot oil provides foods with a desirable, appealing flavor and appearance $[2,3]$. The crispy texture of deep-fat fried foods also enjoys great popularity among the consumers [4].

Moisture loss and fat absorption are the two important mass transports that occur to foods during frying $[5,6]$. These two processes can be adjusted through the change of the raw material property and the frying condition to modify the quality and nutritional attributes of the fried products. Mohammadalinejhad and Dehghannya [7] used ultrasound pretreatment to reduce the fat absorption of potato chips and achieved a maximum reduction of $23.18 \%$. Dueik et al. [8] reduced the oil content of carrot crisps by nearly $50 \%$ by using vacuum frying. Kita [9] found that French fries and potato crisps exhibited more crispy and delicate texture at a higher frying temperature.

For frying, knowledge of mass transfer kinetics enables prediction of food quality changes and permits improvement of product value through proper selection of the frying conditions $[10,11]$. So far, numerous research works relating to deep-fat frying modelling have been described in different fried foods [12-14]. A variety of mathematical models for mass transfer of deep-fat frying are proposed; for example, the first-order kinetic model and the second-order polynomial model for fat absorption $[15,16]$.

Fried battered and breaded fish nuggets (BBFNs), characterized by gold-yellow crispy crust and tender fish meat core, have gained growing popularity in the recent years. Coating the fish nuggets with wheat flour batter and bread crumbs can help the fish meat to retain moisture during deep-fat frying and relieve the negative impact of 
high-temperature oil on the texture and flavor of the fish. Our group has been endeavoring to develop fried fish products with reduced fat content to scale-up the manufacture and has achieved good fat-reducing effect by modifying the batter mix $[17,18]$. To the best of our knowledge, there is currently no study on the mass transfer kinetics of the fried BBFNs. In this research, therefore, kinetics of moisture loss and fat absorption of BBFNs during the frying process at three different temperatures were investigated. This research may help manufacturers to choose a proper frying condition to scale-up the production of fried BBFNs and provide kinetic models to predict the quality change of the products during frying.

\section{Materials and Methods}

2.1. Materials. Fresh grass carp was purchased from a supermarket of the Wuhan Department Store Group Co., Ltd. (Wuhan, China), which was eviscerated, scale-removed, gills-removed, and then stored in a freezer $\left(-20^{\circ} \mathrm{C}\right)$. Corn starch was supplied by Jincheng Co., Ltd. (Zhaoyuan, China). Soybean oil (Golden Dragon Fish) was obtained from the Yihai Kerry Group (Shanghai, China). Plain wheat flour was obtained from the Wuhan Taiyanghang Food Co., Ltd. (Wuhan, China). Bread crumbs (particle size $<2 \mathrm{~mm}$ ) were purchased from the Wuxi Jinhuanghua Food Co., Ltd. (Wuxi, China). Baking powder was obtained from Angel Yeast Co., Ltd. (Yichang, China). Sudan Red B was obtained from Sigma-Aldrich Inc. (St. Louis, USA). Salt was purchased from the Hubei Salt Industry Group Co., Ltd. (Wuhan, China). All other chemicals were of analytical grade unless otherwise stated.

2.2. Preparation of Sample. BBFNs were prepared as previously described [17] with slight modifications. Corn starch (40 g), plain wheat flour (60 g), baking powder ( $1 \mathrm{~g})$, and salt $(2 \mathrm{~g})$ were blended into the batter powder. Deionized water (98 g) was added to the powder and the mixture was stirred with IKA RW20 electric mixer (IKA-Labortechnik, Dottingen, Germany) at a speed of $1000 \mathrm{rpm}$ for $10 \mathrm{~min}$ to form a homogeneous batter. Frozen fish was thawed in running tap water and then cut to nuggets of size $42 \mathrm{~mm} \times 17 \mathrm{~mm} \times 17 \mathrm{~mm}$. The nuggets were deodorized with $2 \%$ green tea at a solid to liquid ratio of $1: 1$ for $2 \mathrm{~h}$. Thereafter, the nuggets were cured by adding 3\% salt for $0.5 \mathrm{~h}$. The cured fish nuggets were immersed into the batter for $10 \mathrm{~s}$, after which the nuggets were taken out and placed on a stainless steel tray for about $15 \mathrm{~s}$. The immersion process was repeated one additional time, and the excess coating was allowed to drain off. The battered nuggets were subsequently rolled in bread crumbs until a uniform coverage was attained. The prepared battered and breaded nuggets were then dried at $40^{\circ} \mathrm{C}$ for $6 \mathrm{~h}$. On average, the coating layer accounted for $27.4 \%$ of BBFNs' weight before frying.

2.3. Frying. In batches of six fish nuggets each, BBFNs were fried in soybean oil $(1.5 \mathrm{~L})$ at $160-180^{\circ} \mathrm{C}\left(160^{\circ} \mathrm{C}, 170^{\circ} \mathrm{C}\right.$, and $180^{\circ} \mathrm{C}$ ) using a YZ-3032-BC deep fryer (Guangdong Youtian
Household Appliances Co., Ltd., Foshan, China) for the required time of $0-180 \mathrm{~s}(0,30,60,90,120,150$, and $180 \mathrm{~s})$, respectively. Fried BBFNs were placed in a wired basket at a temperature of $20^{\circ} \mathrm{C}$ and a relative humidity of $20-30 \%$, allowing for cooling and the removal of excess oil. The crust and core parts of fried products were separated for moisture and fat analysis.

2.4. Moisture and Fat Analysis. Crust and core parts of fried BBFNs were finely ground using a stainless steel scissor until ostensibly homogeneous. The moisture content analysis of the crust and the core were performed by following an oven method obtained gravimetrically after heating at $105^{\circ} \mathrm{C}$ for $4 \mathrm{~h}$. The final moisture content on a dry basis $(\mathrm{g} / \mathrm{g}, \mathrm{db})$ was calculated by taking the difference between the wet and the dry sample weights [19]. The fat content $(\mathrm{g} / \mathrm{g}, \mathrm{db})$ of the crust was measured via the Soxhlet extraction method by using diethyl ether used as the solvent [20].

2.5. Kinetic Modelling for Mass Transfers. For modelling the moisture transfer phenomenon in fried products, Fick's second law of diffusion provides a simplified picture of the moisture loss during frying [11]. The moisture diffusion equation is as follows:

$$
\frac{\partial M}{\partial t}=D \frac{\partial^{2} M}{\partial x^{2}}
$$

where $M$ is the instantaneous moisture (g/g, db), $t$ is time (s), $D$ is the effective diffusion coefficient $\left(\mathrm{m}^{2} / \mathrm{s}\right)$, and $x$ is the position coordinate in the product $(\mathrm{m})$. However, the fried BBFNs could not be set as an individual entity for Fick's second law, because it consists of two parts (the crust and the core), and the initial moisture and the temperature after frying were not evenly distributed. Therefore, the crust was used to be fitted to the Fick's second law.

According to the method of Nasiri et al. [21], the crust of BBFNs was assumed to be an infinite slab, with an initial uniform distribution of moisture and temperature in the crust, and negligible external resistance to mass transfer, with the mass transfer occurring from both sides of the samples. Solution of the above partial differential equation (equation (1)was presented as follows:

$$
M_{r}=\frac{M-M_{e}}{M_{0}-M_{e}}=\frac{8}{\pi^{2}} \sum_{n=0}^{\infty} \frac{1}{(2 n+1)^{2}} e^{-(2 n+1)^{2}\left(\pi^{2} D t / 4 L^{2}\right)},
$$

where $M_{0}$ and $M_{e}$ are the initial and equilibrium moisture content $(\mathrm{g} / \mathrm{g}, \mathrm{db})$, respectively, $L$ is the half thickness of sample $(\mathrm{m})$.

It is reasonable to assume that moisture content is negligible when equilibrium is reached in the frying process, so $M_{\mathrm{e}}=0$. Equation (2) can be simplified as follows to calculate the effective diffusion coefficient:

$$
M_{r}=\frac{M}{M_{0}}=\frac{8}{\pi^{2}} e^{-\left(\pi^{2} D t / 4 L^{2}\right)} .
$$

The first-order kinetic model was used to describe the fat absorption of the crust [6].

$$
\mathrm{FC}=\mathrm{O}_{\mathrm{eq}}\left(1-e^{-k t}\right)
$$


where $\mathrm{FC}$ is the instantaneous fat content $(\mathrm{g} / \mathrm{g}, \mathrm{db}), O_{\text {eq }}$ is the equilibrium fat content $(\mathrm{g} / \mathrm{g}, \mathrm{db})$, and $k$ is the transfer coefficient of fat absorption $\left(\mathrm{s}^{-1}\right)$.

The variation of the effective diffusion coefficient $(D)$ and the equilibrium oil content $\left(O_{\mathrm{eq}}\right)$ with temperature was determined using an Arrhenius-type equation [22]:

$$
\begin{gathered}
D=D_{0} \exp \left(-\frac{E_{a}}{R T}\right), \\
O_{\text {eq }}=O_{0} \exp \left(-\frac{E_{a}}{R T}\right),
\end{gathered}
$$

where $D_{0}$ and $O_{0}$ are the frequency factors, $E_{a}$ is the activation energy $(\mathrm{J} / \mathrm{mol}), R$ is the universal gas constant $(8.314 \mathrm{~J} / \mathrm{mol})$, and $T$ is the absolute temperature in Kelvin.

2.6. Scanning Electron Microscopy (SEM). SEM analysis was performed by using a high vacuum $(<1 \mathrm{~Pa})$ back scattering scanning electron microscope (S-3000 N, Hitachi Co., Ltd., Tokyo, Japan) with a constant voltage of $15 \mathrm{kV}$. All the images were taken at $80 \times$ magnification. Fried BBFNs were cut into $2 \mathrm{~mm} \times 2 \mathrm{~mm} \times 1 \mathrm{~mm}$ size of sheets from the interface between the crust and the core. The sheets were handled by using the $\mathrm{CO} 2$ critical point drying method. The sheets were fixed by using 2.5\% glutaraldehyde and PBS (phosphate buffer saline), then washed by using PBS, followed by dehydration processing sequentially performed with $30-100 \%(30,50,70,90$, and $100 \%)$ ethanol solution, respectively. Finally, anhydrous ethanol and isoamyl acetate were used to replace the ethanol. Specifically, the crust portion, the interface of the crust and the core, and the core portion were scanned. Then photos were taken with the appropriate magnification scans.
2.7. Surface Oil (SO) and Penetrated Surface Oil (PSO) Analysis. SO is the oil adhering to the surface of the fried foods. The SO contents of fried BBFNs were measured according to the method of Bouchon et al. [23] with a slight change. Fried BBFNs were immersed in $150 \mathrm{~mL}$ of petroleum ether for $10 \mathrm{~s}$ at an ambient temperature. The resultant solution was transferred to a $250 \mathrm{~mL}$ round-bottom flask and evaporated under vacuum. The flask was then dried to constant mass at $105^{\circ} \mathrm{C}$ to get the weight of SO.

PSO represents the oil suctioned into the food during cooling after removal from the fryer. The PSO contents of fried BBFNs were determined using the dyed oil-frying method of Yu et al. [24] with a slight modification. Soybean oils with different Sudan Red B contents were heated at $60^{\circ} \mathrm{C}$ for $4 \mathrm{~h}$ to obtain uniform solutions. Each solution was diluted with 20 folds of petroleum ether, and the absorbance was measured at $510 \mathrm{~nm}$ by means of a spectrophotometer. As a result, a calibration curve of dye concentration to absorbance was obtained. The fried BBFNs for PSO analysis were prepared with the same procedure of Section 2.3 except for the addition of Sudan Red B in the oil (concentration $0.5 \mathrm{~g} / \mathrm{L}$ ). The dyed oil-fried BBFNs were immersed in petroleum ether for $10 \mathrm{~s}$ to remove $\mathrm{SO}$, and then were finely cut and dried in a vacuum oven at $50^{\circ} \mathrm{C}$ for $12 \mathrm{~h}$. The dried solids were ground and extracted with petroleum ether using the Soxhlet extraction method for PSO. The extracted oil was evaporated under vacuum and dried to constant mass. The dried oil was diluted with 20 folds of petroleum ether and then measured for absorbance at $510 \mathrm{~nm}$. The concentration of the dye in dried oil can be calculated from a calibration curve, and the PSO content can be calculated using the following equation:

$$
\mathrm{PSO}(\mathrm{g})=\frac{\text { Soxhlet }- \text { extracted oil } \times \text { dye concentration of Soxhlet }- \text { extracted oil }}{\text { dye concentration in frying oil }} .
$$

2.8. Statistical Analysis. Data are expressed as mean \pm standard deviation (SD). Statistical analysis on a completely randomized design was conducted with the analysis of variance (ANOVA) procedure using the SPSS software package (Version 17.0 for windows; SPSS Inc., Chicago, IL, USA). Duncan's multiple range tests were used to compare the difference between mean values at the significance level $(P<0.05)$.

\section{Results and Discussion}

3.1. Moisture Contents of Fried BBFNs. Crust and core moisture contents of BBFNs fried for different durations are shown in Figure 1. The average initial moisture contents of the coating layer and the core were 0.210 and $3.00 \mathrm{~g} / \mathrm{g}(\mathrm{db})$, respectively. At all three frying temperatures, moisture content of the crust decreased with increasing frying time, and the initial $30 \mathrm{~s}$ of frying accounted for the maximum moisture loss. Similar results were found in the frying of shrimp and chicken nuggets
[25-27]. Nasiri et al. [25] ascribed the initial rapid fall of moisture content to the loss of surface moisture. The temperature of hot frying oil was much higher than the boiling point of water. As soon as the BBFNs came in contact with the hot oil, the surface moisture of the batter vaporized intensely. The core exhibited less moisture loss ratio than the crust, suggesting that the coating layer inhibited the moisture loss of the nugget core during the frying process. The core part showed a decreasing tendency in moisture except a slight increase as frying time increased from 30 to $60 \mathrm{~s}$. Ngadi et al. [22] got similar results in the frying of chicken nuggets. The abnormal increase might be ascribed to the increased resistance of moisture transfer and the conflict of heat and moisture flows. Heat would gradually induce starch gelatinization and protein denaturation in the batter, and the swelling effect of these components would increase the resistance of moisture transfer [28]. As the moisture transfer resistance increased, the moisture loss tendency of the core 


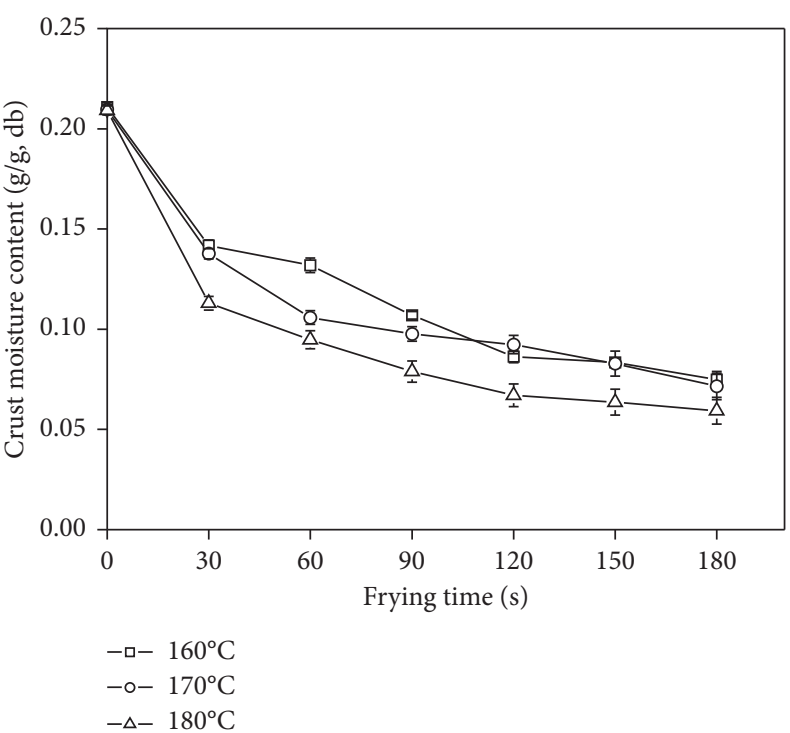

(a)

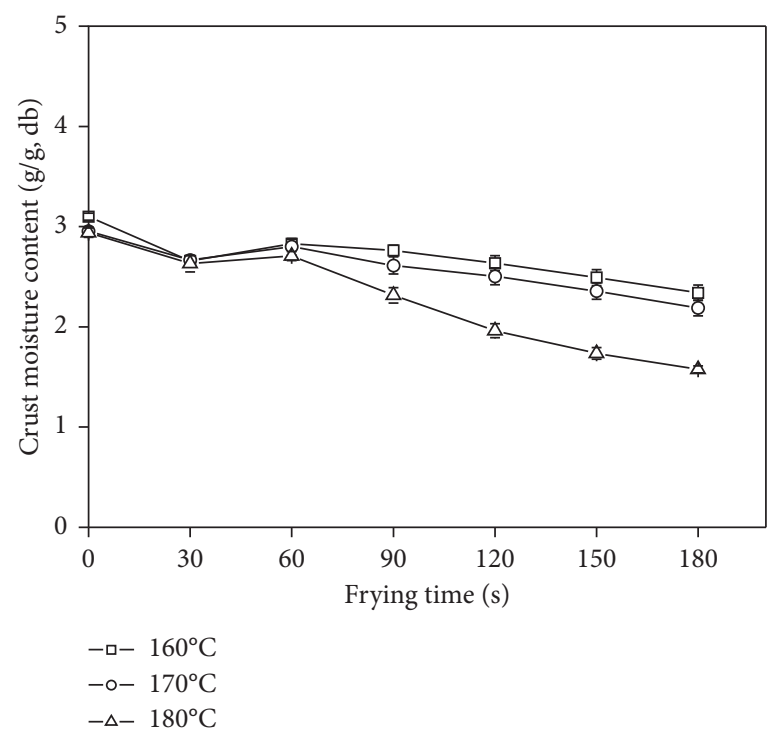

(b)

Figure 1: Crust and core moisture contents of BBFNs fried at different temperatures. (a) Crust; (b) core.

was inhibited. Portion of surface water of the batter might be driven by heat to enter the core, resulting in the temporary increase of core moisture. Figure 1 also shows that higher frying temperature generally caused more moisture loss, both for the crust and core parts. After $180 \mathrm{~s}$ of frying, the crust moisture contents of BBFNs fried at 160,170 , and $180^{\circ} \mathrm{C}$ were $0.0748,0.0714$, and $0.0593 \mathrm{~g} / \mathrm{g}$ (db), respectively; for the core of fried products, the moisture contents were $2.34,2.19$, and $1.58 \mathrm{~g} / \mathrm{g}(\mathrm{db})$, respectively. Similar results were reported for fried shrimp nuggets [25] and "Kroštula" dough [29]. The increase of frying temperature could prompt the heating of BBFNs and accelerated the vaporization of moisture.

3.2. Crust Fat Content of Fried BBFNs. The crust fat contents of BBFNs fried at three temperatures are shown in Figure 2. The average initial fat content of the coating layer was $0.0158 \mathrm{~g} / \mathrm{g}(\mathrm{db})$. At a certain frying temperature, the crust fat content of BBFNs firstly increased with the frying time increasing from 0 to $120 \mathrm{~s}$ and then slightly decreased as the frying time further extended. The dramatic increase of the crust fat content as frying time increased from 0 to $30 \mathrm{~s}$ might be due to the intense vaporization of surface moisture, which leaves voids and pores for the oil to enter later [30]. As the frying time increased from 30 to $120 \mathrm{~s}$, there was a decrease in the increasing trend of fat content. It is generally accepted that fat absorption is heavily linked to moisture loss since it determines the extent of crust formation. In research of fried Gethi strips, Manjunatha et al. [13] found that more moisture loss caused an increase in the fat absorption of the product. Debnath et al. [31] obtained similar results in the frying of chickpea flour-based snack. As discussed above, the reducing trend of the crust moisture decreased after $30 \mathrm{~s}$, correspondingly resulting in a reduced trend of fat absorption. In

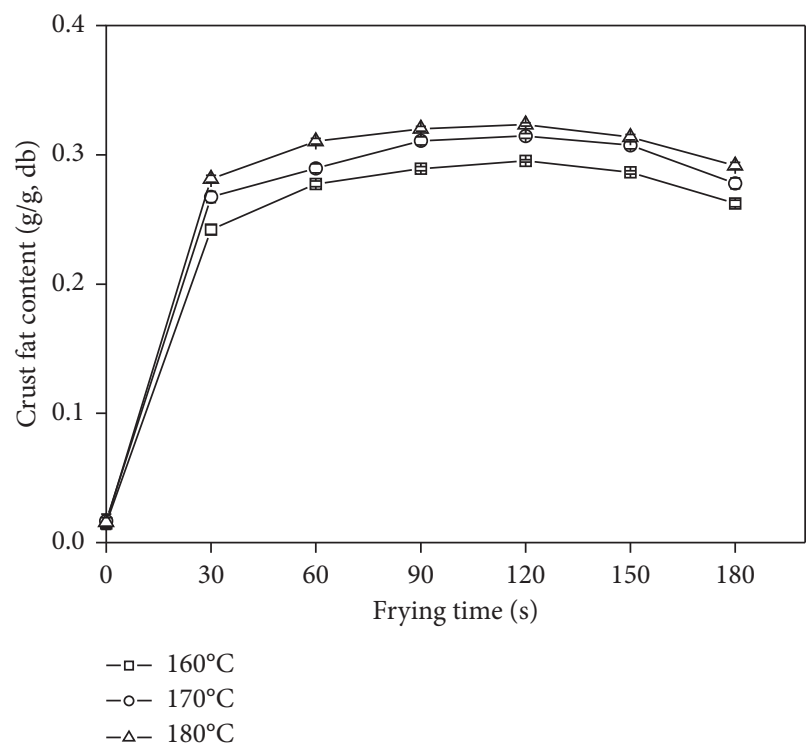

Figure 2: Crust fat content of BBFNs fried at different temperatures.

accordance with Rahimi and Ngadi [32] in the research of fried batter, a slight decrease of crust fat content was observed after a maximum content. This might be attributed to the fat transfer from the crust to the core. Figure 2 also shows that the fat content of the crust generally increased with the increase in the frying temperature. After $180 \mathrm{~s}$ of frying, the crust fat contents of BBFNs fried at 160,170 , and $180^{\circ} \mathrm{C}$ were $0.262,0.278$, and $0.292 \mathrm{~g} / \mathrm{g}(\mathrm{db})$, respectively. Similar results were found in the frying of "Kroštula" dough [29] and chicken meat [33]. Kassama and Ngadi [33] suggested that high frying temperature prompted the formation of the crust, which would facilitate fat absorption. 
TABLE 1: Kinetic parameters and activation energies $\left(E_{a}\right)$ for moisture loss and fat absorption of fried BBFNs ${ }^{\dagger}$.

\begin{tabular}{|c|c|c|c|c|c|c|c|}
\hline \multirow{2}{*}{ Frying temperature $\left({ }^{\circ} \mathrm{C}\right)$} & \multicolumn{3}{|c|}{ Moisture loss } & \multicolumn{4}{|c|}{ Fat absorption } \\
\hline & $D \times 10^{9}\left(\mathrm{~m}^{2} / \mathrm{s}\right)$ & $R^{2}$ & $E_{a}(\mathrm{~kJ} / \mathrm{mol})$ & $k\left(\mathrm{~s}^{-1}\right)$ & $O_{\text {eq }}(\mathrm{g} / \mathrm{g}, \mathrm{db})$ & $R^{2}$ & $E_{a}(\mathrm{~kJ} / \mathrm{mol})$ \\
\hline 160 & $5.05 \pm 0.05^{\mathrm{c}}$ & 0.94 & & $0.055 \pm 0.001^{\mathrm{c}}$ & $0.295 \pm 0.001^{\mathrm{c}}$ & 0.95 & \\
\hline 170 & $5.50 \pm 0.10^{\mathrm{b}}$ & 0.89 & $11.46 \pm 0.61$ & $0.059 \pm 0.002^{b}$ & $0.315 \pm 0.002^{b}$ & 0.93 & $7.67 \pm 0.22$ \\
\hline 180 & $5.81 \pm 0.05^{\mathrm{a}}$ & 0.85 & & $0.066 \pm 0.002^{\mathrm{a}}$ & $0.324 \pm 0.001^{\mathrm{a}}$ & 0.92 & \\
\hline
\end{tabular}

${ }^{\dagger}$ Data were expressed as mean \pm SE $(n=3)$. Data with the same letter in the same column were not significantly different at a significance level of 0.05 .
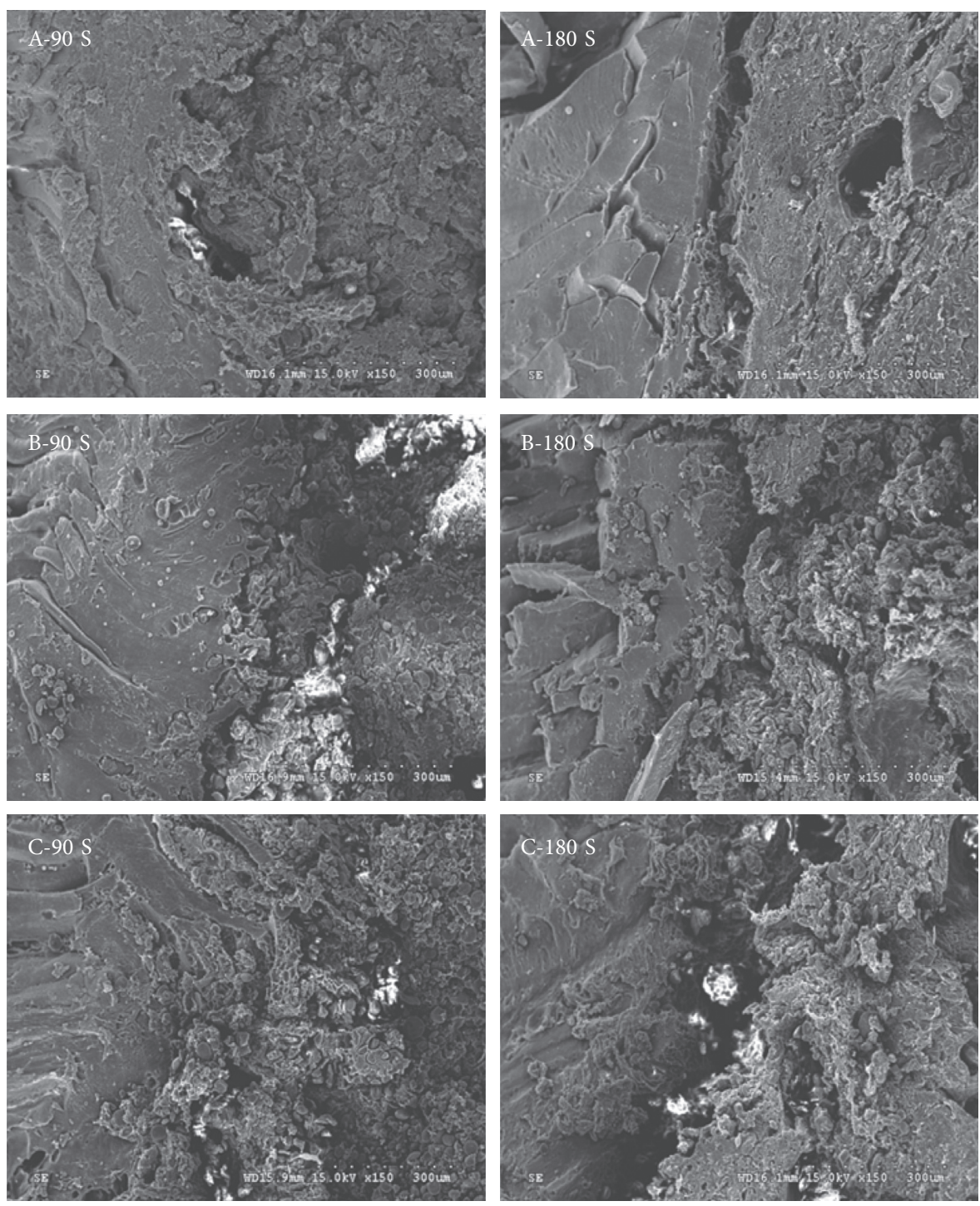

Figure 3: SEM images of BBFNs fried at different frying temperatures. (A) $160^{\circ} \mathrm{C}$; (B) $170^{\circ} \mathrm{C}$; (C) $180^{\circ} \mathrm{C}$.

3.3. Kinetic Model of Mass Transfer. The data of crust moisture and fat contents were fitted to Fick's second law of diffusion and the first-order kinetic model, respectively, and the obtained model parameters are shown in Table 1. As Table 1 shows, correlation coefficients $\left(R^{2}\right)$ of three fittings for moisture loss kinetics were between 0.85 0.94, suggesting that the Fick's law model could well describe the moisture loss of the fried crust. The $D$ values of the frying processes at 160,170 , and $180^{\circ} \mathrm{C}$ were $5.05 \times 10^{-9}$,
$5.50 \times 10^{-9}$, and $5.81 \times 10^{-9} \mathrm{~m}^{2} / \mathrm{s}$, respectively. This result suggested that the increase in the frying temperature accelerated the moisture loss of the crust. Similar results were reported on frying of the breaded chicken nuggets [26] and "Kroštula" dough [29]. The correlation coefficients of three fittings for fat absorption kinetics were between 0.92 0.95 (Table 1), suggesting that the first-order kinetic model could well describe the fat absorption of the crust. The $k$ values of frying processes at 160,170 , and $180^{\circ} \mathrm{C}$ were 


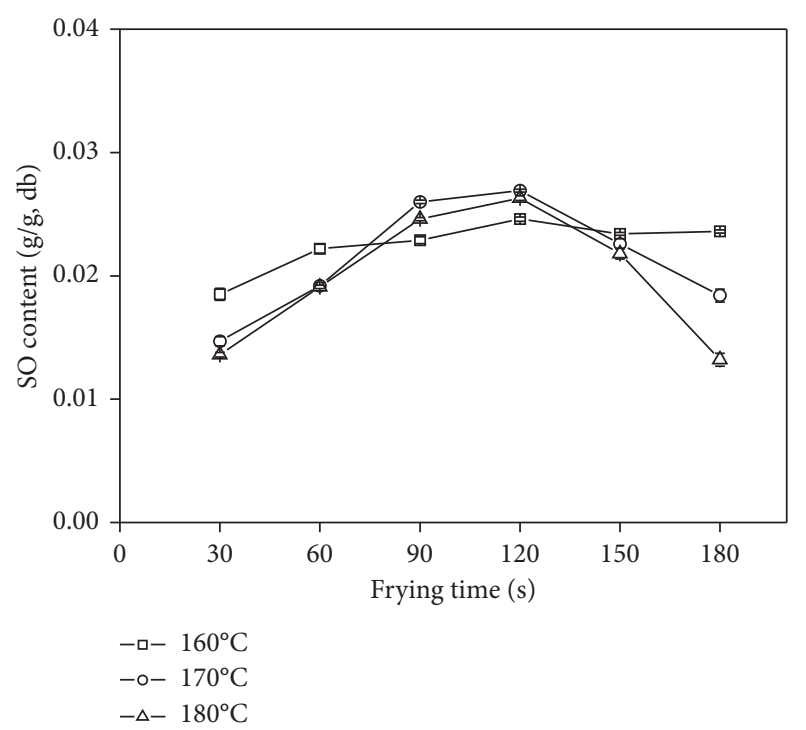

(a)

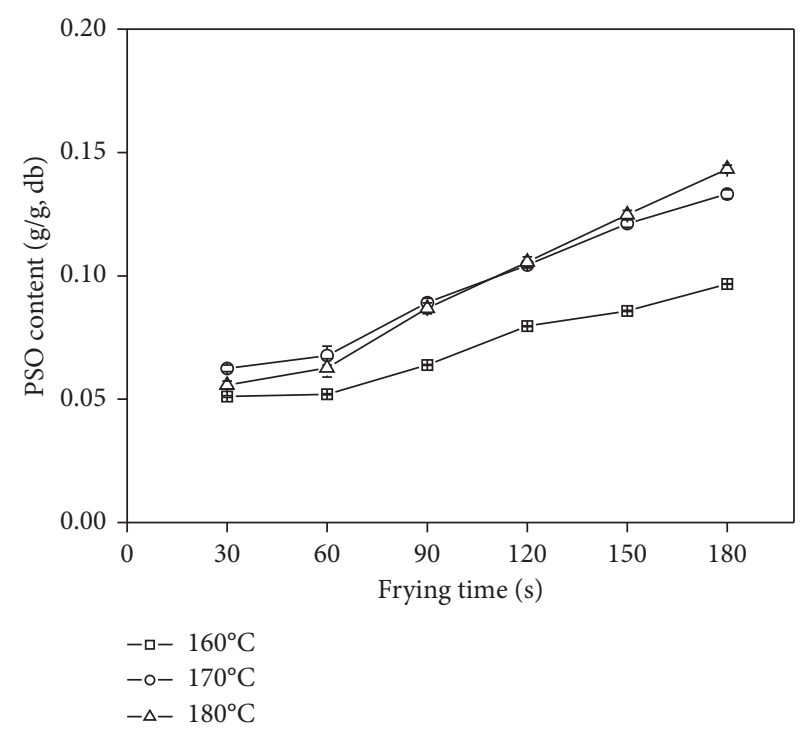

(b)

FIGURE 4: SO and PSO contents of BBFNs fried at different temperatures. (a) SO; (b) PSO.

$0.055,0.059$, and $0.066 \mathrm{~s}^{-1}$, respectively. This result suggested that fat absorption of the crust was accelerated with increasing frying temperature. Similar results were reported for fried Gethi strips [13] and chicken nuggets [34]. Activation energies $\left(E_{a}\right)$ of moisture loss and fat absorption were 11.46 and $7.67 \mathrm{~kJ} / \mathrm{mol}$, respectively.

3.4. SEM. SEM images of fried BBFNs are depicted in Figure 3. As Figure 3 shows, for BBFNs fried at all three frying temperatures, pore size of the crust increased as the frying time increased. This result was consistent with Adedeji et al. [35], whose research utilized confocal laser scanning microscopy to observe the batter microstructure of fried chicken nuggets. Taiwo and Baik [36] reported a similar trend for the porosity of fried sweet potatoes. It can be found from the comparison of SEM images of BBFNs fried at different temperatures that pore size of fried BBFNs increased as the frying temperature increased. The change of the crust microstructure was in accordance with the change of the crust in moisture and fat contents. Adedeji and Ngadi [37] reported similar results in the research of fried chicken nuggets, which suggested that an increase of porosity resulted in an increase of routes for moisture loss and fat absorption.

3.5. SO and PSO Contents. SO and PSO contents of fried BBFNs are shown in Figure 4. As frying time increased, SO contents of BBFNs fried at all three temperatures firstly increased and then decreased, but PSO contents exhibited steady trends of increase. This result suggested that more surface fat penetrated into the inner part of the crust with prolonged frying time. Similar results were reported in the case of fried batter [32] and potato slices [38]. Bouchon et al. [23] also observed the increase of PSO in fried potato chips, and they ascribed this result to the increase of pores. Pore size of the crust increased as frying time prolonged, allowing the oil to enter easily into the structure during cooling. It can be found from the comparison of SO and PSO contents of BBFNs fried at three different temperatures that higher frying temperature generally caused more penetration of fat. This result was in accordance with the SEM images. Similar results were also reported in the case of fried potato slices [38].

\section{Conclusions}

Crust moisture content of fried BBFNs decreased with the increase in the frying time. Moisture content of the core exhibited a general decreasing trend except for a slight increase at an early frying stage. Fat content of the crust firstly increased to a maximum level and then decreased. The increase in the frying temperature increased the moisture loss of both the crust and the core, and also increased the fat absorption of the crust. The moisture loss and fat absorption of BBFNs during deep-fat frying can be well described by Fick's second law of diffusion and the first-order kinetic model, respectively. The mass transfer coefficients of moisture loss and fat absorption increased with elevated frying temperature. The PSO content of the crust increased with the increase in the frying temperature. High frying temperature increased the pore size of the crust. These results suggest that the frying temperature influenced the moisture loss and the fat absorption of the crust by changing its microstructure.

\section{Data Availability}

All data and analyses are included as figures and tables within the manuscript.

\section{Conflicts of Interest}

The authors declare that they have no conflicts of interest. 


\section{Acknowledgments}

This work was supported by the National Natural Science of China (Grant no. 31471612), the China Agriculture Research System (Grant no. CARS-45), Hubei Agricultural Achievements Transformation (Grant no. NZZ2018000014), and the Open Fund of Key Laboratory for Deep Processing of Major Grain and Oil, Wuhan Polytechnic University, Ministry of Education (Grant no. 2020JYBQGDKFB09).

\section{References}

[1] J. Song, M.-J. Kim, Y.-J. Kim, and J. Lee, "Monitoring changes in acid value, total polar material, and antioxidant capacity of oils used for frying chicken," Food Chemistry, vol. 220, pp. 306-312, 2017.

[2] Q. Zhang, C. Wan, C. Wang et al., "Evaluation of the nonaldehyde volatile compounds formed during deep-fat frying process," Food Chemistry, vol. 243, pp. 151-161, 2018.

[3] I. H. Mondal and K. K. Dash, "Textural, color kinetics, and heat and mass transfer modeling during deep fat frying of chhena jhili," Journal of Food Processing and Preservation, vol. 41, Article ID e12828, 2017.

[4] E. Mah and R. G. Brannan, "Reduction of oil absorption in deep-fried, battered, and breaded chicken patties using whey protein isolate as a postbreading dip: effect on flavor, color, and texture," Journal of Food Science, vol. 73, no. 1, pp. S412-S417, 2009.

[5] A. B. Oyedeji, O. P. Sobukola, F. O. Henshaw, M. O. Adegunwa, L. O. Sanni, and K. I. Tomlins, "Kinetics of mass transfer during deep fat frying of yellow fleshed cassava root slices," Heat and Mass Transfer, vol. 52, no. 5, pp. 1061-1070, 2016.

[6] R. Moreira, J. Palau, and X. Sun, "Simultaneous heat and mass transfer during the deep fat frying of tortilla chips," Journal of Food Process Engineering, vol. 18, no. 3, pp. 307-320, 2010.

[7] S. Mohammadalinejhad and J. Dehghannya, "Effects of ultrasound frequency and application time prior to deep-fat frying on quality aspects of fried potato strips," Innovative Food Science \& Emerging Technologies, vol. 47, pp. 493-503, 2018.

[8] V. Dueik, P. Robert, and P. Bouchon, "Vacuum frying reduces oil uptake and improves the quality parameters of carrot crisps," Food Chemistry, vol. 119, no. 3, pp. 1143-1149, 2010.

[9] A. Kita, "The effect of frying on fat uptake and texture of fried potato products," European Journal of Lipid Science and Technology, vol. 116, no. 6, pp. 735-740, 2014.

[10] O. P. Sobukola and P. Bouchon, "Mass transfer kinetics during deep fat frying of wheat starch and gluten based snacks," Heat and Mass Transfer, vol. 50, no. 6, pp. 795-801, 2014.

[11] M. E. Sosa-Morales, R. Orzuna-Espíritu, and J. F. Vélez-Ruiz, "Mass, thermal and quality aspects of deep-fat frying of pork meat," Journal of Food Engineering, vol. 77, no. 3, pp. 731-738, 2006.

[12] P.-Y. Huang and Y.-C. Fu, "Relationship between oil uptake and water content during deep-fat frying of potato particulates under isothermal temperature," Journal of the American Oil Chemists' Society, vol. 91, no. 7, pp. 1179-1187, 2014.

[13] S. S. Manjunatha, N. Ravi, P. S. Negi, P. S. Raju, and A. S. Bawa, "Kinetics of moisture loss and oil uptake during deep fat frying of Gethi (Dioscorea kamoonensis Kunth) strips," Journal of Food Science and Technology, vol. 51, no. 11, pp. 3061-3071, 2014.
[14] M. K. Krokida, V. Oreopoulou, and Z. B. Maroulis, "Water loss and oil uptake as a function of frying time," Journal of Food Engineering, vol. 44, no. 1, pp. 39-46, 2000.

[15] K. Neethu, M. E. E. Franklin, H. A. Pushpadass, R. R. Menon, K. J. Rao, and B. S. Nath, "Analysis of transient heat and mass transfer during deep-fat frying of Pantoa," Journal of Food Processing and Preservation, vol. 39, no. 6, pp. 966-977, 2015.

[16] A. Odenigbo, J. Rahimi, M. Ngadi, D. Wees, A. Mustafa, and P. Seguin, "Quality changes in different cultivars of sweet potato during deep-fat frying," Journal of Food Processing \& Technology, vol. 3, no. 5, p. 156, 2012.

[17] J. Shan, J. Chen, D. Xie, W. Xia, W. Xu, and Y. L. Xiong, "Effect of xanthan gum/soybean fiber ratio in the batter on oil absorption and quality attributes of fried breaded fish nuggets," Journal of Food Science, vol. 83, no. 7, pp. 1832-1838, 2018.

[18] H. Zeng, J. Chen, J. Zhai, H. Wang, W. Xia, and Y. L. Xiong, "Reduction of the fat content of battered and breaded fish balls during deep-fat frying using fermented bamboo shoot dietary fiber," LWT-Food Science and Technology, vol. 73, pp. 425-431, 2016.

[19] AOAC, No. 934.01, Official Methods of Analysis of AOAC International, 934, 1996.

[20] AOAC, No. 991.36, Official Methods of Analysis of AOAC International, 991, 36, 1996.

[21] F. D. Nasiri, M. Mohebbi, F. T. Yazdi, and M. H. H. Khodaparast, "Kinetic modeling of mass transfer during deep fat frying of shrimp nugget prepared without a pre-frying step," Food and Bioproducts Processing, vol. 89, pp. 241-247, 2011.

[22] M. Ngadi, K. Dirani, and S. Oluka, "Mass transfer characteristics of chicken nuggets," International Journal of Food Engineering, vol. 2, pp. 1-16, 2006.

[23] P. Bouchon, J. M. Aguilera, and D. L. Pyle, "Structure oilabsorption relationships during deep-fat frying," Journal of Food Science, vol. 68, no. 9, pp. 2711-2716, 2003.

[24] L. Yu, J. Li, S. Ding, F. Hang, and L. Fan, "Effect of guar gum with glycerol coating on the properties and oil absorption of fried potato chips," Food Hydrocolloids, vol. 54, pp. 211-219, 2016.

[25] F. D. Nasiri, M. Mohebbi, F. T. Yazdi, and M. H. H. Khodaparast, "Effects of soy and corn flour addition on batter rheology and quality of deep fat-fried shrimp nuggets," Food and Bioprocess Technology, vol. 5, no. 4, pp. 1238-1245, 2012.

[26] A. A. Adedeji, M. O. Ngadi, and G. S. V. Raghavan, "Kinetics of mass transfer in microwave precooked and deep-fat fried chicken nuggets," Journal of Food Engineering, vol. 91, no. 1, pp. 146-153, 2009.

[27] S. Lalam, J. S. Sandhu, P. S. Takhar, L. D. Thompson, and C. Alvarado, "Experimental study on transport mechanisms during deep fat frying of chicken nuggets," LWT-Food Science and Technology, vol. 50, no. 1, pp. 110-119, 2013.

[28] S. Lee and G. E. Inglett, "Functional characterization of steam jet-cooked? Glucan-rich barley flour as an oil barrier in frying batters," Journal of Food Science, vol. 71, no. 6, pp. E308-E313, 2006.

[29] S. Budžaki and B. Šeruga, "Moisture loss and oil uptake during deep fat frying of "kroštula" dough," European Food Research \& Technology, vol. 220, no. 1, pp. 90-95, 2005.

[30] M. Mellema, "Mechanism and reduction of fat uptake in deep-fat fried foods," Trends in Food Science \& Technology, vol. 14, no. 9, pp. 364-373, 2003.

[31] S. Debnath, K. K. Bhat, and N. K. Rastogi, "Effect of predrying on kinetics of moisture loss and oil uptake during deep 
fat frying of chickpea flour-based snack food," $L W T-$ Food Science and Technology, vol. 36, no. 1, pp. 91-98, 2003.

[32] J. Rahimi and M. O. Ngadi, "Effect of batter formulation and pre-drying time on oil distribution fractions in fried batter," LWT-Food Science and Technology, vol. 59, no. 2, pp. 820826, 2014.

[33] L. S. Kassama and M. O. Ngadi, "Pore development in chicken meat during deep-fat frying," $L W T$-Food Science and Technology, vol. 37, no. 8, pp. 841-847, 2004.

[34] M. Soorgi, M. Mohebbi, S. M. Mousavi, and F. Shahidi, "The effect of methylcellulose, temperature, and microwave pretreatment on kinetic of mass transfer during deep fat frying of chicken nuggets," Food and Bioprocess Technology, vol. 5, no. 5, pp. 1521-1530, 2012.

[35] A. A. Adedeji, L. Liu, and M. O. Ngadi, "Microstructural evaluation of deep-fat fried chicken nugget batter coating using confocal laser scanning microscopy," Journal of Food Engineering, vol. 102, no. 1, pp. 49-57, 2011.

[36] K. A. Taiwo and O. D. Baik, "Effects of pre-treatments on the shrinkage and textural properties of fried sweet potatoes," LWT-Food Science and Technology, vol. 40, no. 4, pp. 661668, 2007.

[37] A. A. Adedeji and M. Ngadi, "Porosity determination of deepfat-fried coatings using pycnometer (Fried batter porosity determination by pycnometer)," International Journal of Food Science \& Technology, vol. 46, no. 6, pp. 1266-1275, 2011.

[38] F. Pedreschi, C. Cocio, P. Moyano, and E. Troncoso, "Oil distribution in potato slices during frying," Journal of Food Engineering, vol. 87, no. 2, pp. 200-212, 2008. 